\title{
ESTUDO DA MICRO-BACIA DO CÓRREGO CAÍ-GUAÇU (ANHUMAS/SP)
}

Bruno Cardoso ; Gabriele Paes de Lima; Geraldo Augusto Ferdin; João Vitor; Mariana Andrade; Nathalia Caroline Lopes Guidio; Rodrigo Domingues Scatolon.

Universidade do Oeste Paulista, curso de Engenharia Ambiental, Presidente Prudente, SP. E-mail: marianaengamb@outlook.com

\section{RESUMO}

A utilização incorreta dos recursos naturais e da ocupação e uso do solo trouxeram problemas ambientais graves, como a erosão e contaminação de cursos d'agua, e por isso houve um crescimento na demanda de estudos que buscam identificar, gerenciar e recuperar (quando possíveis) os danos causados no meio. Partindo dessa necessidade o presente estudo buscou levantar informações sobre o uso e ocupação do solo pertencente à microbacia do córrego CaiGuaçu. Utilizando métodos de analises bibliográficas, questionários, uso de softwares e visitas à campo para identificar as características físicas da mesma. Obtendo resultados alarmantes, como a falta da vegetação em áreas destinadas a preservação do manancial e grande voçoroca, foi possível realizar gráficos para ilustrar as características fieis da microbacia, assim como trazer átona para as futuras pesquisas uma base para comparação. Com isso concluímos que há a necessidade da implantação de medidas emergenciais de para a preservação e recuperação da mesma.

Palavras-chave: recursos, impacto, bacia, hidrologia, gestão.

\section{STUDY STREAM WATERSHED CAÍ-GUAÇU (ANHUMAS/SP)}

\begin{abstract}
Incorrect use of natural resources, occupation and land use brought serious environmental problems, such as erosion and contamination of watercourses and so there was a growing demand for studies that seek to identify, manage and recover (when is possible) damage the environment. From this need the present study sought to gather information on the use and occupation of land belonging to the watershed Cai Guacu stream. Using methods of literature analysis, questionnaires, use of software and visits to the field to identify the physical characteristics of the same. Getting alarming results, as the lack of vegetation in areas for preservation of wealth and large gully, it was possible to make graphs to illustrate the faithful characteristics of watershed, as well as bring unstressed for future research a basis for comparison. With this we conclude that there is the need to implement emergency measures for the preservation and recovery of the same.
\end{abstract}

Keywords: resource, impact, basin, hydrology, management. 
INTRODUÇÃO

A utilização dos recursos naturais impacta primeiramente o seu local de retirada ou de inserção de materiais, e nos últimos anos tem-se adotado a Bacia Hidrográfica como sendo a unidade territorial a ser considerada nos estudos desses impactos, e na elaboração de planos de recuperação, tendo os recursos hídricos papel de destaque nos levantamentos e planejamentos.

Segundo a SEMARH (Secretaria de Estado do Meio Ambiente e dos Recursos Hídricos) entende-se por Bacia Hidrográfica, a área drenada por um rio ou um sistema conectado de rios (riachos, córregos) tal que toda a vazão efluente é descarregada através de uma simples saída. A formação da bacia hidrográfica dá-se através dos desníveis dos terrenos que orientam os cursos da água, sempre das áreas mais altas para as mais baixas.

A Região de Presidente Prudente faz parte do comitê do Pontal do Paranapanema, que engloba 26 municípios do Oeste Paulista; e tem como Presidente a prefeita de Rosana, Sandra Aparecida de Souza Kasai.

Em entrevista com o Secretário Executivo do comitê de bacia do Pontal do Paranapanema e representante do DAEE, o Sr. Sandro Roberto Selmo, nos foi relatado que com relação as verbas: partem dos municípios, entidades, instituições privadas e do FEHIDRO, a competência é do município, que deve_apresentar uma notificação sobre os problemas da bacia, para que o comitê em conjunto com patrocinadores crie um projeto de recuperação que deverá ser executado pelo município e pelos patrocinadores, sendo que, as verbas partiram dos patrocinadores ou do FEHIDRO. Esses projetos são denominados de AREA DE PRESERVAÇÃO E RECUPERAÇÃO DE MANANCIAL.

Segundo Dibieso (2007) o rio Cai Guaçu é um dos principais afluentes do Ribeirão Noite Negra que é um afluente do Rio Santo Anastácio. A Bacia do Santo Anastácio é de especial importância, pois é estratégica em relação ao abastecimento público do município de Presidente Prudente. Anhumas possui uma área municipal de $320,4 \mathrm{~km}^{2}$ e está à $505,8 \mathrm{~km}$ da capital São Paulo. A vegetação da região é composta pelo bioma Mata Atlântica. E sua população em 2014 de 3.970 habitantes.

O trecho da bacia referente a microbacia do Caí Guaçu é composto por solos tipo: Pva1(podzólico vermelho-amarelo abruptico álico epidistrófico), Ae3 (Associação de solos aluviais epirutróficos + distróficos + eutróficos + glei.), PEa8 (associação de podzólico vermelho escuro álico epidistrófico + podzólico vermelho-amarelo eutrófico + podzólico vermelho-amarelo álico epidistrófico, todos abrupticos) e Ad4 (associação de solos aluviais distróficos, eutróficos e glei.) (Dibieso, 2007). 
O objetivo do presente estudo foi levantar as características físicas da microbacia do córrego Cai-Guaçu, assim como os possíveis impactos ambientais sofridos pela mesma devido ao uso e ocupação do solo.

\section{METODOLOGIA}

Nesta presente pesquisa foi utilizado a pesquisa bibliográfica e descritiva. Inicialmente partiu-se da determinação de uma área de bacia hidrográfica que tivesse fácil acesso, e extensão limitada ao tempo disponível para o estudo de campo, está observação foi feita a partir de carta topográfica da região de Anhumas - SP.

Para melhor conduzir a coleta de informações foram elaborados critérios para o levantamento, levando em consideração os moradores, uso e ocupação do solo e as características das propriedades. Posteriormente foram determinados os dias e horários de visita à Bacia, e os equipamentos e materiais utilizados, para nossa proteção e para melhor detectar as informações da área. Utilizando materiais de proteção e materiais de auxílio para melhor coletar as informações. Também no início da pesquisa determinou-se os assuntos teóricos que foram levantados com base em pesquisa bibliográfica, e posteriormente conforme vieram surgindo novas indagações.

\section{RESULTADOS E DISCUSSÕES}

A bacia em questão não possui residências, dificultando a entrevista com os proprietários, no entanto, em uma das visitas a bacia, encontramos um proprietário colhendo café, (Ivo Sotocorno - Estância 4 Irmãos) nos forneceu algumas informações. A maioria das propriedades na região possuem 20 alqueires. Na propriedade pertencente ao senhor Ivo Sotocorno existem cerca de 44 cabeças de gado confinado para produção de leite, 120 cabeças no total, 11 alqueires de café, e milho para silo. O CAR da propriedade foi realizado, o rio_está cercado e com mata ciliar.

A área total da bacia é de 290,53 ha, e o curso d'agua possui cerca de 5,11 km de extensão. Apenas 13,61 ha são de área de APP (área de preservação permanente) reflorestada; e 24,55 ha de vegetação total implantada no município. A área ocupada por culturas é de 38,20 há e de pastagem é 227,78 há. 


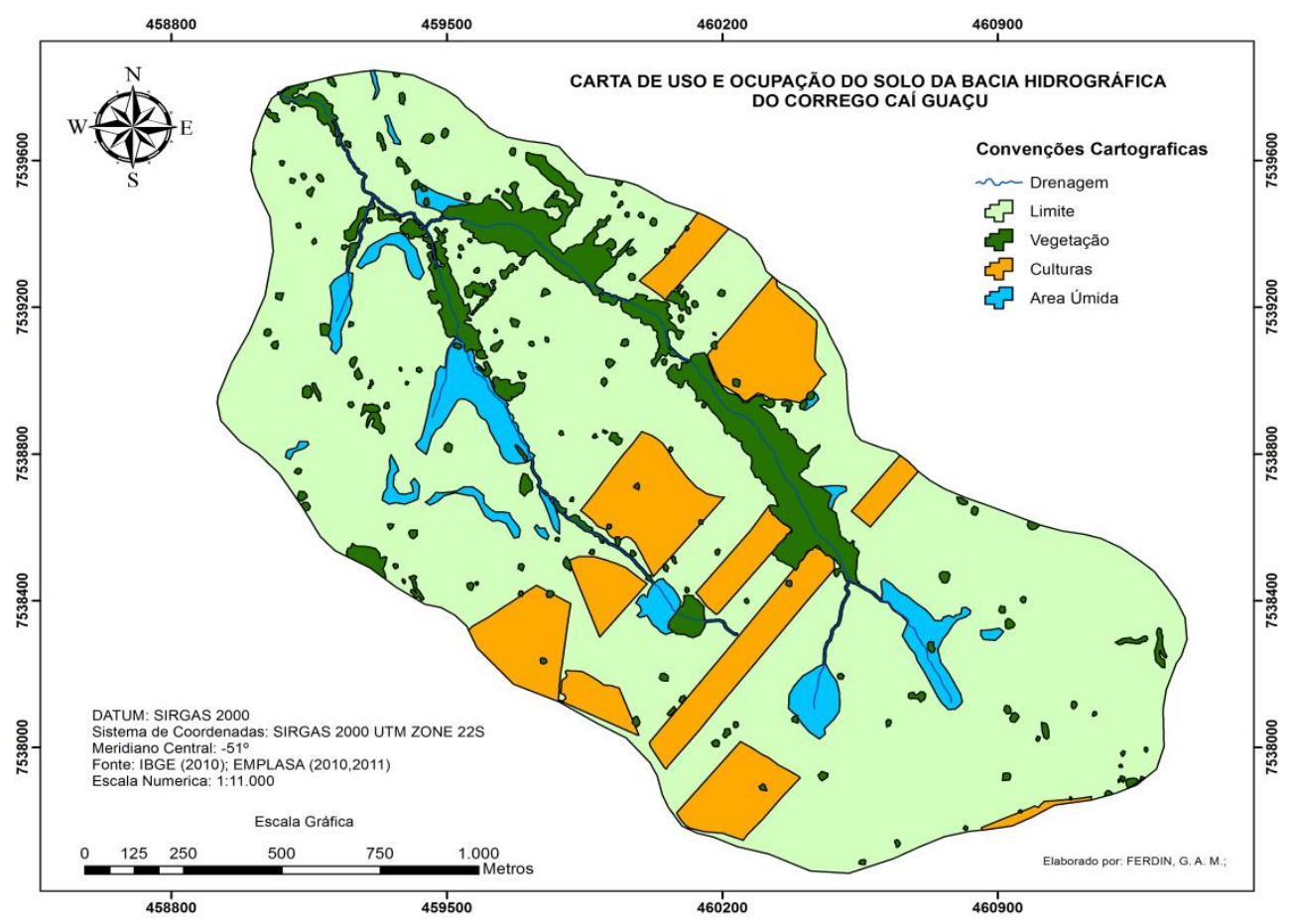

Figura 1. Carta de Uso e Ocupação do Solo da Bacia Hidrográfica do Córrego Caí-Guaçu.

Fonte: Os autores

Dentre os problemas levantados estão o assoreamento do córrego, voçoroca, erosões nas encostas, animais no curso d'agua, barramento irregular e falta de vegetação em zonas destinadas a APP.

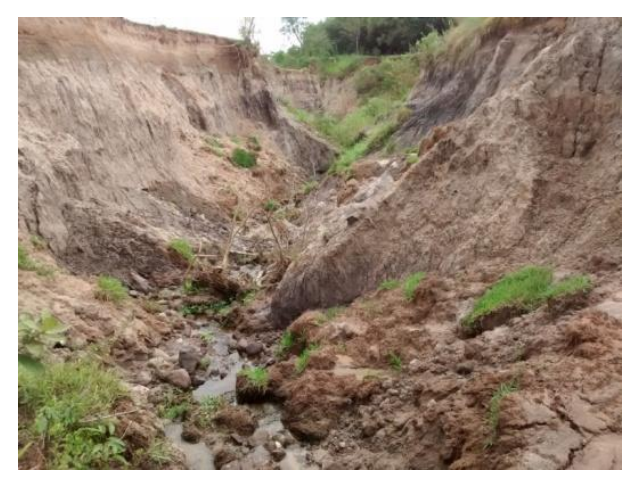

Figura 2. Voçoroca

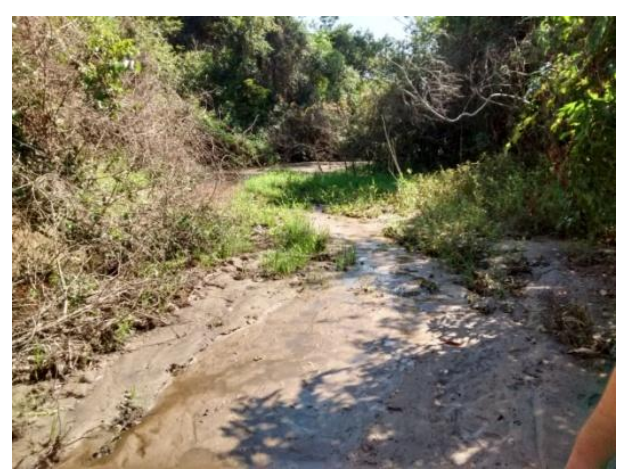

Figura 3. Assoreamento

Fonte: Os autores.

\section{CONCLUSÃO}

Com base no estudo teórico e levantamento de campo realizado, pode-se notar a relação das características do solo da bacia, com a interação do mesmo com as intempéries, e a importância de um manejo adequado dos recursos ali presentes, pois mesmo com a ausência de residências, os impactos da atuação humana na bacia hidrográfica do Caí Guaçu são consideráveis. 
Com isso concluímos que há a necessidade da implantação de medidas emergenciais de para a preservação e recuperação da mesma.

\section{REFERÊNCIAS}

ANA. Sobre a ANA. SD. Disponível em:

<http://www2.ana.gov.br/Paginas/institucional/SobreaAna/Default.aspx>.

CNRH. Conselho Nacional de Recursos Hídricos. SD. Disponível em:

<http://www.cnrh.gov.br/index.php?option=com_content\&view=article\&id=1:0-conselhonacional-de-recursos-hidricos-cnrh\&catid=1:0-conselho-nacional-de-recursos-hidricos-

cnrh\&Itemid=36>.

DIBIESO, Eduardo Pizollim. Planejamento ambiental da bacia hidrográfica do córrego do cedro Presidente Prudente/SP. 2007.

DIBIESO, Eduardo Pizollim; LEAL, Antoneo Cezar. Uso da água na bacia hidrográfica do manancial do alto curso do rio Santo Anastácio/SP. SD.

GUEDES, Ivan Claudio; et al. Análise de perfis longitudinais de drenagens da bacia do rio santo anastácio (sp) para detecção de possíveis deformações neotectônicas. 2006.

IBGE. Anhumas: histórico. $2011 . \quad$ Disponível em:< http://cidades.ibge.gov.br/painel/historico.php?lang=\&codmun=350240>.

IBGE. Censo Agropecuário. 2006. Disponível em: < http://cidades.ibge.gov.br/xtras/temas.php?lang=\&codmun=350240\&idtema=3\&search=saopaulo|anhumas|censo-agropecuario-2006>.

JUNIOR, Salvador Carpi; LEAL, Antoneo Cezar. Mapeamento de riscos ambientais e planejamento participativo no manancial Rio Santo Anastácio - UGRHI Pontal do Paranapanema - SP. 2012.

MANZATO, Antônio José; SANTOS, Adriana Barbosa. A elaboração de questionários na pesquisa quantitativa. 2012 Disponível em: <http://www.inf.ufsc.br/ verav/Ensino_2012_1/ELABORACAO_QUESTIONARIOS_PESQUISA_QUA NTITATIVA.pdf $>$.

OBSERVATÓRIO DO CÓDIGO FLORESTAL. O Código Florestal. SD. Disponível em: < http://www.observatorioflorestal.org.br/pagina-basica/o-codigo-florestal>.

PENSAMENTO VERDE. O antigo e novo Código Florestal brasileiro: o que mudou?. 2013. disponível em: <http://www.pensamentoverde.com.br/governo/o-antigo-e-novo-codigo-florestal-brasileiroo-que-mudou/>.

SEADE. Território. 2013, Secretária do Meio Ambiente do Estado de SP. Disponível em: <http://produtos.seade.gov.br/produtos/anuario/2003/1_intro.pdf>. 
SECRETARIA DE MEIO AMBIENTE. Município Verde Azul. SD. Disponível em: $<$ http://www.ambiente.sp.gov.br/municipioverdeazul/>.

SIGRH. Recursos hídricos. SD. Disponível em: < http://www.sigrh.sp.gov.br>.

SILVA, Leonice Aparecida da. As Áreas de Preservação Permanente (APP's) dos Corpos d água Urbanos: um Espaço Híbrido. SD.

SILVA, Carlos Eduardo; ALMEIDA, Josimar Ribeiro. Recuperação de voçorocas na zona rural do município de Mineiros (GO): financeiramente viável e ambientalmente sustentável. 2011.

SUA PESQUISA. IDH - Índice de Desenvolvimento Humano. SD. Disponível em: < http://www.suapesquisa.com/o_que_e/idh.htm>. 